CASE REPORTS

\title{
Proptosis following head injury in children with reticulosis
}

\author{
P. Kothandaram \\ M.S., F.R.C.S. (Edin.) \\ Senior Registrar, Department of Neurological Surgery, Royal Manchester Children's Hospital, \\ Pendlebury, Manchester
}

THE TWO patients described below entered the Neurosurgical Service of the Children's Hospital with bilateral proptosis occurring after a minor head injury. Both of the patients were in fact suffering from reticulosis but the condition had been previously unsuspected.

In the first patient evidence of generalized reticulosis was not apparent for some months after the head injury had precipitated his proptosis.

In the second case, brought to hospital because of proptosis developing after a minor head injury, good evidence of the presence of generalized reticulosis was manifest at the time of admission.

Bilateral proptosis as a consequent of head injury is very rare, and ocular manifestations of reticulosis even rarer.

\section{Case 1}

Brian C. R.M.C.H. No. 36454, born 16 February 1966. In October 1967, the child, aged 1 year 8 months, attended a medical paediatric clinic with loose stools and pallor. Physical examination of the patient did not reveal any abnormality.

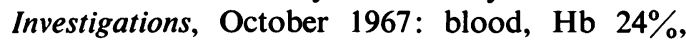
WBCs $6700 / \mathrm{mm}^{3}$, ESR $15 \mathrm{~mm} / \mathrm{hr}$. Stools were cultured and no organisms were grown. Bone marrow studies did not reveal any abnormality. A blood transfusion corrected the anaemia and the diarrhoea remitted.

Three months later (January 1968), the child had a fall at his nursery school, hitting the back of his head on the concrete floor. He vomited once or twice following the fall but was apparently all right after this. A few days later prominence of the eyes was noted, particularly on the left side. He became increasingly irritable with periods of drowsiness. In February 1968 (3 weeks after the fall), he was referred to the Neurosurgical Unit because of increasing prominence of the eyes and irritability.

Examination: The child appeared pale and fretful. Both eyes were prominent with oedema of the lids and conjunctivae. The cornea appeared healthy, the left eye was more prominent than the right. Eye movements were restricted in all directions (Fig. 1). The fundi were normal. Examination of the

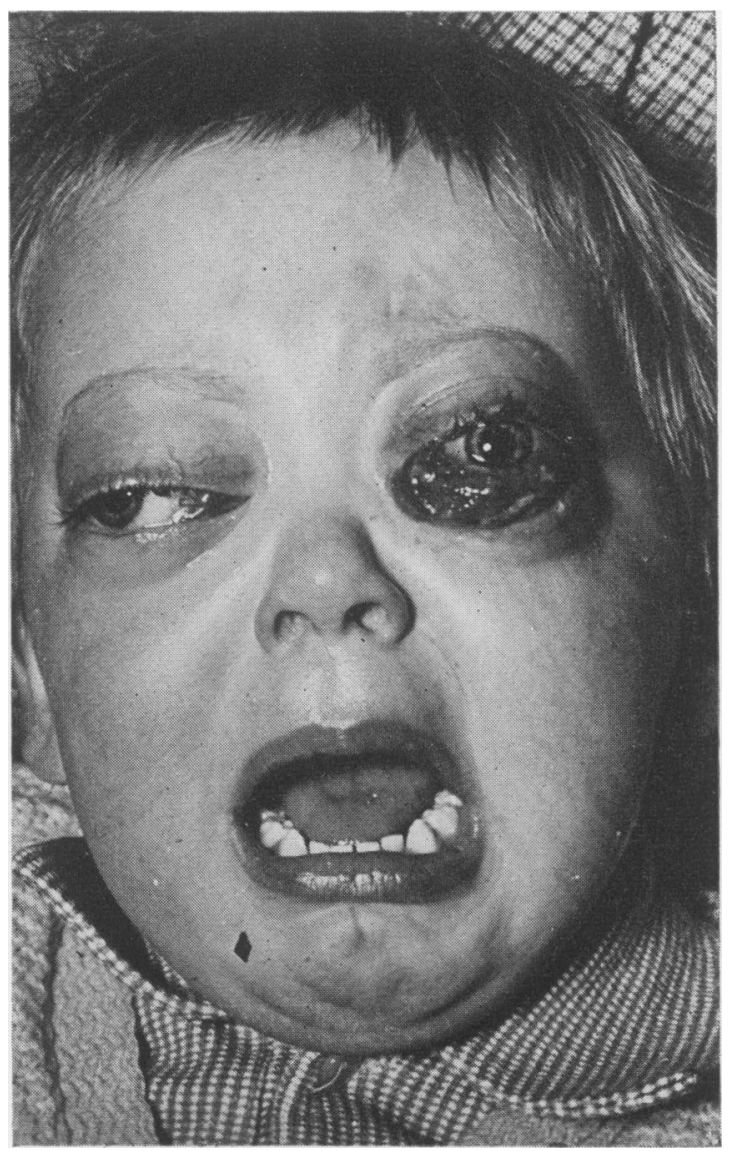

Fig. 1. Brian C. Pre-operative bilateral proptosis. Note oedema of the conjunctiva on the left side. 
central nervous system was normal. He had one finger's width enlargement of the liver. No enlargement of other lymph nodes in the body.

Investigations, February 1968: blood, $\mathrm{Hb} 76 \%$, WBCs $6400 / \mathrm{mm}^{3}$, platelets $168,000 / \mathrm{mm}^{3}$, differential count, P $70 \%$, L $23 \%$, M $6 \%$, E $1 \%$, ESR $20 \mathrm{~mm} / \mathrm{hr}$. Initial bone marrow appearances were accepted as normal. X-ray of the skull and chest, including detailed views of the orbit and bilateral carotid angiograms were normal. Urinary catecholamine excretion was $1 \cdot 1 \mu \mathrm{g} / 24 \mathrm{hr}$.

Progress: The orbital proptosis steadily increased and it looked as if there was a danger that the cornea might ulcerate due to exposure keratitis.

Tarsorrhaphy of the left eye was performed. The proptosis continued to increase and the tarsorrhaphy sutures began to cut through. A transfrontal decompression of the orbits was undertaken on 7 March 1968 as an urgent measure. Greyish tumour mass was removed from each orbit and a satisfactory decompression of the orbits was achieved. After 2 weeks the child showed considerable improvement (Fig. 2).

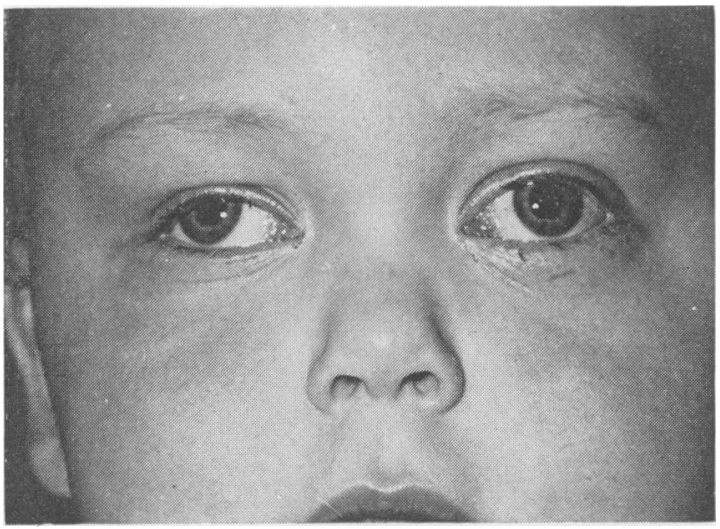

FIG. 2. Brian C. Two weeks post-operative. Note complete regression of proptosis.

Histology (Dr H. B. Marsden): 'Infiltration of the orbital fat by polygonal cells with delicate chromatin and scanty mitoses (Fig. 3a). The appearance suggested reticulum cell sarcoma.' Further review of the earlier marrow slides (Fig. 3b) showed scanty reticulum cells and a diagnosis of generalized reticulosis was established. Vincristine $0.8 \mathrm{mg}$ i.v. was given twice a week for the first 3 weeks postoperatively. Later cyclophosphadmide $50 \mathrm{mg} /$ day and prednisolone $25 \mathrm{mg}$ /day was instituted. The child was discharged home on this therapy and was then reviewed once a week, for periodic checks of the white cell count. In April 1968 the child was started on chlorambucil $4 \mathrm{mg}$ and prednisolone $25 \mathrm{mg}$ daily.

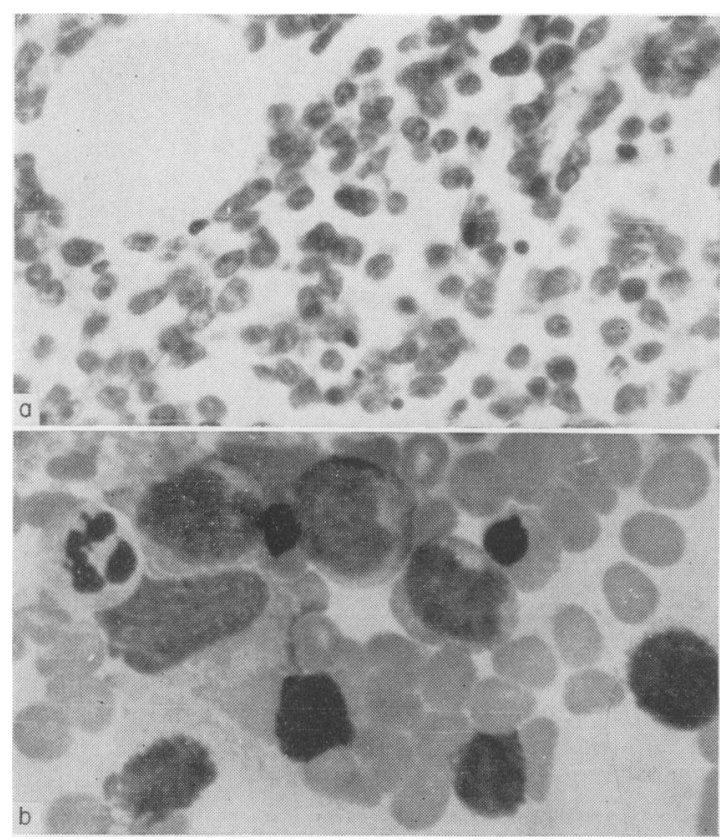

Fig. 3. Brian C. (a) Orbital fat with ovoid polygonal and spherical tumour cells. High power. (b) Marrow with scattered tumour cells.

The patient was well until August 1968 (that is 5 months after the operation) when he was re-admitted to hospital with vomiting, drowsiness and fever. $\mathrm{He}$ had been in contact with Varicella Minor at home and soon after admission to hospital developed generalized petechial haemorrhages of the skin and succumbed to a fulminating encephalitis. At necropsy generalized petechial haemorrhages throughout the mucous membranes were seen. There was no evidence of the reticulosis; it had apparently been cleared by the cytotoxic agents.

\section{Case 2}

Kathleen W. R.M.C.H. No. 50/3499, aged 3 years. In February 1951, the patient fell down a flight of stairs banging her head on the floor. There was no loss of consciousness. One week later, black discolouration appeared around the eyes. The discolouration disappeared from the right eye but reappeared 1 week later. The eyes became more and more prominent and the patient began to complain of headaches (Fig. 4). She was fretful and nervous. Six weeks after the fall, in April 1951, the child was referred to the Neurosurgical Unit.

On examination there was generalized pallor and fretfulness. Both eyes were prominent, particularly the left eye which was displaced downwards, upward gaze was limited. The pupils were equal and reacted to light. The fundi were normal. Conjunctivae and 
cornea were normal. A small firm swelling in the right supraorbital region and another about $\frac{3}{4}$ in. long on the inner edge of the left canthus was present. Neurological examination was normal. The liver was enlarged two to three finger breadths and firm in consistency.

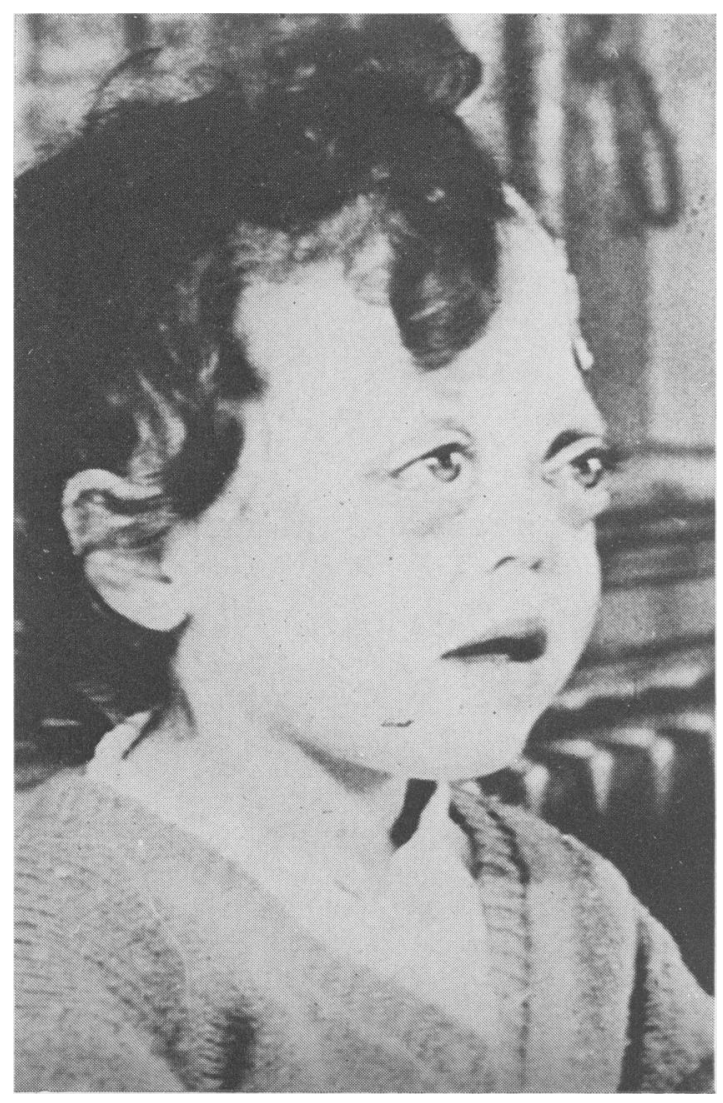

FIG. 4. Kathleen W., aged 3. Bilateral proptosis following head injury. Case of myeloreticulosis.

Investigations: $\mathrm{Hb} 42 \%$, WBCs $6300 / \mathrm{mm}^{3}, \mathrm{P} 41 \%$, L $41 \%$, M 12\%, E 5\%, B 1\%, ESR 76 mm/hr. X-ray of the skull showed radiating spicules in the right supraorbital region. X-ray of the long bones was normal.

Bone marrow (Dr H. B. Marsden): 'The majority of the cells were of promocyte type. Reticulum cells showed marked fat-storage and are plasmacytoid. The condition suggested an acute reticulosis. Fat storage is thought to be a secondary feature compatible to these extreme forms seen in some reticulosarcomas.' Riopsy of the soft tissue deposit near the eye revealed it to be a myeloreticulosis with orbital deposits. The child was referred for radiotherapy but it was thought that the disease was too far advanced to benefit from radiotherapy. Tarsorrhaphy was done to prevent ulceration of the cornea. The haemoglobin remained at $30-40 \%$, in spite of repeated transfusions. Three days prior to death, immature cells were noticed in the peripheral blood. Permission for necropsy was not granted.

\section{Discussion}

Bilateral progressive orbital proptosis is a most unusual sequel to head injury. The cause of proptosis in the cases described proved to be reticulosis and the trauma seems to have played some part in producing the orbital symptoms. Forrest (1949) reported 222 orbital tumours, in which twenty-five were derived from blood-forming organs, and out of these twenty-five only four were lymphomas and these four occurred in patients between the ages of 30 and 40. There were no children in the series. Heath (1949) reviewed 1600 ocular tumours; sixty-seven were orbital lymphomas and again these were adult patients. Mortada \& El-Ashmawy (1967) reported two cases of proptosis in infants who were suffering from aleukaemic lukaemia, both proving fatal within 1 month. Most of the orbital lymphomas reported are derived from either the lacrimal gland, the conjunctivae or the periorbital structures. Since lymph nodes are not present within the orbit the origin of these lymphomas is from lymphatic channels within orbital structures.

Unilateral involvement of the orbit is not an uncommon feature of leukaemia, chloroma and Hand-Schüller Christian disease. In such cases there is usually unmistakable evidence of disease elsewhere. The interesting feature of Case 1 is that the tumour seemed to have become manifest in the orbit, and only after several months was there clear evidence of generalized reticulosis.

The histological distinction between various types of lymphomas or reticulosis is somewhat artificial; most of the cell types are different stages of the same disease process. Changes in the peripheral blood are very rare and may only be noticed in the terminal cases. In Case 2 changes in the peripheral blood were noticed 3 days prior to fatal termination. The ultimate prognosis is better where the disease is confined to the orbits (Schulz \& Heath, 1948), as in Case 1, as opposed to ocular deposits which occur secondary to reticulosis elsewhere.

These cases have been both a diagnostic as well as a management problem. Most of the ophthalmologists preferred to biopsy the orbital contents by a direct approach. The transcranial route with orbital decompression has the added advantage of dealing with both orbits at the same time, giving an adequate decompression, as well as obtaining satisfactory biopsy. Cytotoxic drugs are preferable to radiotherapy because of the satisfactory response 
and the generalized nature of the disease process. Where disease is localized to one particular region as the orbit, radiotherapy may be preferable.

\section{Acknowledgments}

I wish to thank Mr B. H. Dawson, Consultant Neurosurgeon, and $\mathrm{Dr}$ H. B. Marsden, Consultant Pathologist, R.M.C.H., for their help.

\section{References}

FORREST, A.W. (1949) Intraorbital tumours. Archives of Ophthalmology, 41, 198.

Heath, P. (1949) Ocular lymphomas. American Journal of Ophthalmology, 32, 1213.

Mortada, A. \& El-Ashmawy, S. (1967) Aleukaemic leukaemia and exophthalamos in children. Bulletin of the Ophthalmic Society of Egypt, 6, 165.

Schulz, M.D. \& Heath, P. (1948) Lymphoma of the conjunctiva. Radiology, 50, 500.

\title{
Listeria monocytogenes meningitis in adults: a report of two cases
}

\author{
C. J. MORAN \\ B.Sc., M.B., Ch.B. \\ Senior House Officer, Department of Medicine, Southmead Hospital, Bristol
}

ThE Gram-Positive bacillus Listeria monocytogenes is widespread in the animal kingdom but not a common pathogen in man (Gray, 1962). Since its first isolation by Murray, Webb \& Swann in 1926 its appearances in this role are increasing. It most frequently causes a meningitis in the very young (Edmunds, Nicholson \& Douglas, 1957) but may present as a septicaemic condition in the foetus or newborn (Granulomatosis infantiseptica, Harding \& Brunton, 1962; Beck, O'Brien \& Mackenzie, 1966), as an infectious mononucleosis-like syndrome (Girard \& Murray, 1951) or on the genitalia, when it may cause habitual abortion (Toaff, Krochik \& Rabinovitz, 1962; MacNaughton, 1962). Pustular conditions of the skin and conjunctivitis are also described, particularly in veterinary workers. (Owen et al., 1960).

When it causes meningitis in the adult, it typically singles out debilitated patients and those on steroids (Ford, Herzberg \& Ford, 1968). Healthy individuals are also susceptible and twenty-one cases are recorded in the English literature (Finegold et al., 1954; Binder et al., 1957; Dedrick, 1957; Welshimer \& Winglewish, 1959; Whitty \& Macaulay, 1965; Librach \& Seth, 1961).

The diagnosis is seldom immediately apparent. It may be delayed because the organism is dismissed in bacteriological preparations, or it may not grow at all under ordinary conditions (Gray, 1962). A source of infection is rarely identified (Beck, 1961).

The following two patients, both presenting in the same area within a year are reported to emphasize the occurrence of Listeria monocytogenes meningitis in healthy adults.

\section{Case reports}

\section{Case 1}

A 46-year-old lorry driver was admitted on 28 July 1968, with a 24-hr history of back and neck pain of acute onset. He complained of severe headache. There was no relevant past history.

On examination his temperature was $105^{\circ} \mathrm{F}$ $\left(40 \cdot 6^{\circ} \mathrm{C}\right)$ pulse $80 / \mathrm{min}$. He was confused and agitated. Neck stiffness was present. There were no enlarged lymph glands or photophobia, and tendon jerks and plantar responses were normal. Kernig's test was negative.

Lumbar puncture: The CSF pressure was normal, and the glucose and protein levels were $45 \mathrm{mg} / 100$ $\mathrm{ml}$ and $230 / 100 \mathrm{ml}$. The white cell count was $340 / \mathrm{mm}^{3}$ (70\% lymphocytes). No organisms were seen on a Gram-stained preparation. 